\title{
Model Tangki untuk Menghemat Konsumsi Daya Pompa pada Sisi Discharge
}

\section{Tank Models to Save Pump Power Consumption on the Discharge Side}

\author{
Budhi Martana*1), Muhammad Galbi Bethalembah²) dan Fahrudin ${ }^{3)}$ \\ Program Studi Teknik Mesin, Fakultas Teknik, \\ Universitas Pembangunan Nasional Veteran Jakarta, Indonesia
}

Diterima: April 2020; Disetujui: Mei 2021; Dipublikasi: Mei 2021;

*Coresponding author: budhi.martana@upnvi.ac.id

\begin{abstract}
Abstrak
Penelitian ini bertujuan untuk menghasilkan tangki prototipe yang mampu meringankan kerja pompa khususnya meningkatkan head tekan pompa pada sisi discharge. Metode penelitian yang digunakan adalah riset development dengan langkah-langkah sebagai berikut: (1) menetapkan definisi fungsi dan spesifikasi, (2) membuat rancangan desain model tangki prototipe untuk menghemat daya pompa, (3) melakukan pengujian dan simulasi kinerja model tangki hasil rancangan. Hasil pengujian menunjukan bahwa penerapan gaya gravitasi pada tangki zat cair yang terletak pada elevasi tertentu dari sumbu pompa memiliki potensi besar untuk meningkatkan head statis tekan pompa atau dapat mereduksi konsumsi daya pada sisi discharge pompa hingga 100\% termasuk rugi-rugi pada sisi discharge dengan jalan memperbesar kapasitas tangki. Disamping itu untuk memperoleh efektifitas gaya gravitasi yang terpakai, maka pemilihan material apung dan batang pendorong harus seringan mungkin.

Kata Kunci: tangki, gaya gravitasi, pompa, discharge.
\end{abstract}

\begin{abstract}
This study aims to produce a prototype tank that is able to ease the work of the pump, especially increasing the pump head press on the discharge side. The research method used is development research with the following steps: (1) determining the definition of functions and specifications, (2) designing a prototype tank model design to save pump power, (3) testing and simulating the performance of the design tank model. The test results show that the application of gravity on the liquid tank located at a certain elevation from the pump axis has a great potential to increase the pump's static head or can reduce power consumption on the pump discharge side up to $100 \%$ including losses on the discharge side by enlarging tank capacity. Besides that, to obtain the effectiveness of the gravitational force used, the selection of buoyancy material and the driving rod must be as light as possible.
\end{abstract}

Keywords: tank, gravity, pump, discharge.

How to Cite: Martana, Budhi, Muhammad Galbi Bethalembah \& Fahrudin (2021). Model Tangki untuk Menghemat Konsumsi Daya Pompa pada Sisi Discharge. JIME (Journal of Industrial and Manufacture Engineering). 5(1): 15 - 19 
Budhi Martana, Muhammad Galbi Bethalembah \& Fahrudin. Model Tangki untuk Menghemat Konsumsi Daya Pompa pada Sisi Discharge

\section{PENDAHULUAN}

Penggunaan tangki penampung air semakin meningkat seiring dengan bertambahnya jumlah penduduk, karena air merupakan salah satu kebutuhan primer manusia.

Tangki pada dasarnya dipakai sebagai tempat penyimpanan material baik berupa benda padat, cair, maupun gas. Proses pengisian tangki penampung atau tangki cadangan dari pompa yang diterapkan selama ini adalah dengan mengupayakan agar tekanan yang ada dalam tangki sama dengan tekanan atmosfir, agar tidak ada tambahan tekanan yang terjadi.

Ketika air disuplai dari pompa menuju tangki maka perlahan volume air yang masuk kedalam tangki yang bertekanan atmosfer akan mengisi ruang yang berisi udara. Untuk mencegah tekanan udara dalam tangki melebihi tekanan atmosfer maka pada tangki disediakan katup pelepas udara ke atmosfer. Semakin banyak air yang masuk kedalam tangki akan semakin besar pula gaya dorong kebawah akibat berat air, sehingga tangki akan bergerak kebawah relatif terhadap piston. Gaya dorong inilah yang menciptakan ekspansi volume udara yang ada dalam tangki.

Penggunakan model tangki pada pompa bertujuan untuk membuat tekanan atmosfir sama dengan tekanan yang ada dalam tangki, dengan demikian dapat menghemat daya pompa pada sisi keluar (discharge).

Penelitian ini bertujuan menghasilkan tangki prototipe yang mampu meringan beban kerja pompa, secara khusus meningkatkan head tekan pompa sehingga terjadi penghematan daya input pompa sebesar daya yang diperlukan pada sisi discharge.

Perancangan adalah bagian dari kegiatan rekayasa yang merupakan usaha secara intelektual untuk memenuhi tuntutan-tuntutan tertentu dengan cara sebaik mungkin. Pengertian rekayasa adalah penerapan ilmu dan matematik untuk memanfaatkan benda dan energi dalam alam ini sehingga berguna bagi manusia dalam kegiatan pembuatan bangunan, permesinan, produk, sistem, dan proses. Perancangan adalah tahapan perancangan (design) memiliki tujuan untuk mendesain sistem baru yang dapat menyelesaikan masalah-masalah yang dihadapi perusahaan yang diperoleh dari pemilihan alternatif sistem yang terbaik.

Menurut Hukum Archimedes gaya berat dan gaya ke atas suatu benda jika dimasukan kedalam air yaitu Suatu benda yang dicelupkan sebagian atau seluruhya kedalam zat cair akan mengalami gaya ke atas yang besarnya sama dengan berat zat cair yang dipindahkan oleh benda tersebut. Hukum Boyle menyatakan bahwa Tekanan dan volume dari suatu gas adalah berbanding terbalik pada masa gas dan suhu yang konstan (isotermis), yang berarti bahwa tekanan naik, volume turun dan sebaliknya volume naik dan tekanan turun.

Pompa adalah suatu alat atau mesin yang digunakan untuk memindahkan cairan dari suatu tempat ke tempat yang lain melalui suatu media perpipaan dengan cara menambahkan energi pada cairan yang dipindahkan dan berlangsung secara terus menerus. Pompa beroperasi dengan prinsip membuat perbedaan tekanan antara bagian masuk (suction) dengan bagian keluar (discharge). Dengan kata lain, pompa berfungsi mengubah tenaga 
mekanis dari suatu sumber tenaga (penggerak) menjadi tenaga kinetis (kecepatan), dimana tenaga ini berguna untuk mengalirkan cairan dan mengatasi hambatan yang ada sepanjang pengaliran.

\section{METODE PENELITIAN}

Metode penelitian yang digunakan adalah riset development dengan langkahlangkah sebagai berikut: (1) menetapkan definisi fungsi dan spesifikasi, membuat rancangan desain model tangki prototipe untuk menghemat daya pompa, (3) melakukan pengujian dan simulasi kinerja model tangki hasil rancangan.

Penelitian ini menggunakan perangkat lunak (software) Solid Works Simulation untuk membuat gambar rancangan dan melakukan simulasi yang dilakukan berdasarkan data input sebagai berikut: (1) Waktu simulas $\mathrm{i}=10$ s (simulasi yang dilakukanhanya pada 10 detik pertama sejakair dimasukan), (2) Debit air inlet $=30 \mathrm{~L} /$ menit, (3) Volume Tank $=150$ Liter, dan (4) K Pegas $=0.87 \mathrm{~N} / \mathrm{m}$.

\section{HASIL DAN PEMBAHASAN}

Tahap awal kegiatan penelitian dimulai dengan mengumpulkan data dan informasi mengenai model tangki untuk penyimpanan yang dapat menghemat daya pada pompa. Proses pembuatan gambar rancangan menggunakan software Solid Works Simulation untuk mendapatkan gambar rancangan. Untuk mendapatkan performa dari model tangki rancangan yang optimal maka dimensi dari tangki mengacu pada penelitain yang sebelumnya. Berdasarkan hasil desin acuan maka dapat disajikan secara umum seperti pada gambar 1 dibawah ini.

Proses perancangan (design) dibuat berdasarkan dari perhitungan yang mengacu pada spesifikasi tangki air yang akan digunakan sehingga dapat ditemukan spesifikasi yang sesuai dengan kebutuhan dari tangki air hemat energi. Tahapan dalam mendesain ini dimulai dengan menentukan gaya-gaya yang terjadi pada tangki air dan bouy dilanjutkan dengan menentukan dimensi awal dan jenis material yang akan digunakan, proses perhitungan dengan Microsoft Office Excel 2016.

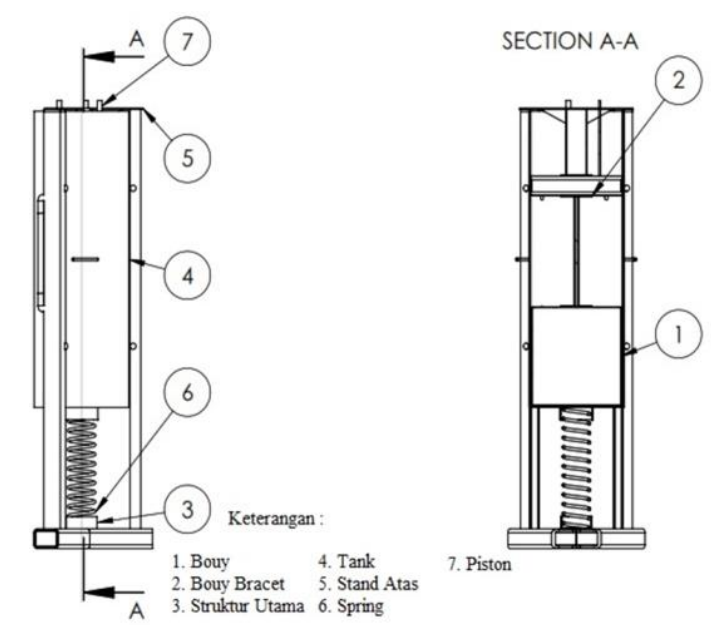

Gambar 1. Model Tangki Rancangan

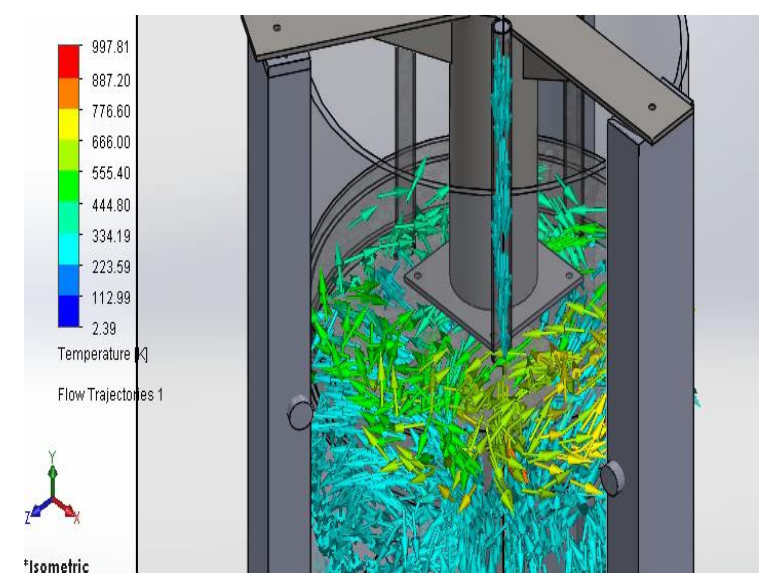

Gambar 2. Simulasi CFD dengan FlowSimulation SolidWorks Tempratur (K)

Ketika air disuplai dari pompa menuju tangki maka perlahan volume air yang masuk kedalam tangki yang bertekanan atmosfer akan mengisi ruang yang berisi udara. Untuk mencegah tekanan udara dalam tangki melebihi tekanan atmosfer maka pada tangki disediakan katup pelepas udara ke atmosfer. Semakin banyak air yang masuk kedalam 
Budhi Martana, Muhammad Galbi Bethalembah \& Fahrudin. Model Tangki untuk Menghemat Konsumsi Daya Pompa pada Sisi Discharge

tangki maka semakin besar pula gaya dorong kebawah akibat berat air dan oleh pelampung terhadap piston pada kedudukan tetap, maka tangki akan bergerak kebawah relatif terhadap piston.

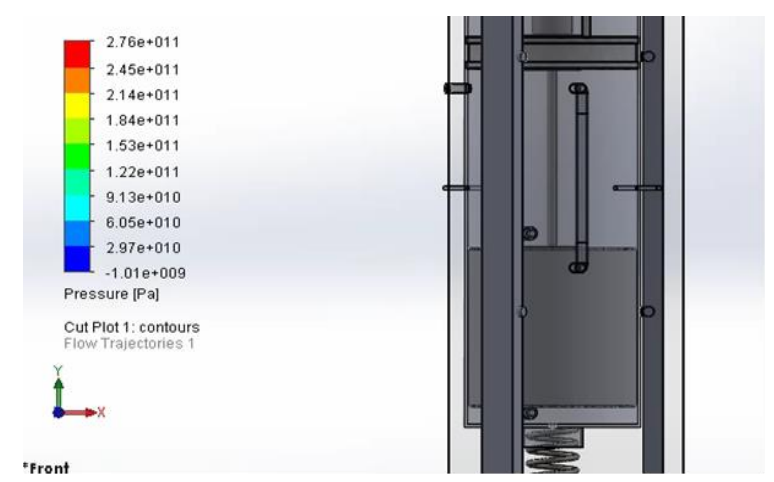

Gambar 3. Simulasi CFD dengan FlowSimulation SolidWorks Cut Plot Pressure (Pa)

Seiring dengan meningkatnya jumlah cairan yang masuk kedalam tangki, maka tekanan dalam tangki akibat pergerakan tangki tertutup kearah bawah akan mengikuti fenomena tekanan negatif, dimana volume air yang masuk adalah sama dengan volume udara yang keluar dikurangi volume yang terjadi akibat berat air ditambah dengan volume yang terjadi akibat gaya apung yang merupakan fenomena turunnya tangki (pergerakan tangki kebawah). Dengan demikian laju defleksi pegas harus lebih besar daripada peningkatan laju tinggi pada tank. Jika $Q=$ laju volume air yang masuk kedalam tangki (liter/menit), maka tinggi cairan pada tangki sebesar laju volume air dikalikan dengan waktu alir dibagi luas penampang tangki, dimana lendutan pegas yang terjadi adalah total gaya kebawah dibagi dengan kekakuannya atau sama dengan kecepatan rata-rata kebawah dikalikan dengan waktu yang digunakan (makin tinggi permukaan cairan pada tangki makin besar pula lendutan pegas yang terjadi). Untuk mengoptimalkan efek gaya apung, maka tiang pelampung akan dibuat seringan mungkin dan untuk mengantisipasi penciutan tangki walau sangat kecil karena akan berpengaruh pada piston isap maka akan dipertimbangkan menggunakan cincin fleksibel seperti pada engine piston.

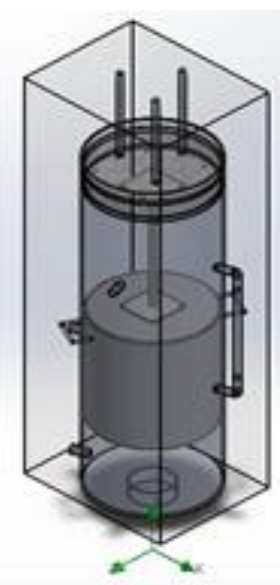

Gambar 4. Simulasi CFD dengan FlowSimulation SolidWorks Velocity $(\mathrm{m} / \mathrm{s})$

Tabel 1. Kondisi Pada Model Tangki Rancangan

\begin{tabular}{lrr}
\hline \multicolumn{1}{c}{ Kondisi Tangki } & Kosong (W1) & Penuh (W2) \\
\hline Volume Tangki Air & 11485270.63 & 11485270.63 \\
Massa Jenis Tangki & 8.000 & 8.000 \\
Berat Tangki & 900.4452324 & 900.4452324 \\
Volume Air & 0 & 96322076.51 \\
Massa Jenis Air & 997 & 997 \\
Berat Air & 0 & 941.1244807 \\
Volume Buoy & 43284191.28 & 43284191.28 \\
Gaya Apung & 0 & 422.9125193 \\
\hline
\end{tabular}

Tabel 1 menunjukkan gaya yang terjadi pada sistem ada dua parameter gaya yang diperhatikan yaitu gaya yang tetap dan gaya yang berubah. Gaya yang tetap antara lain adalah berat dari tangki air (berat dari bouy diabaikan karena bouy dikopel dengan rangka atau Mainframe), sedangkan gaya yang berubah adalah volume air dan gaya apung dari bouy dimana gaya apung dari bouy dipengaruhi oleh volume air itu sendiri. Volume air 
yang diperhatikan adalah volume air pada kondisi kosong dan volume air pada kondisi penuh. Pada saat volume air kosong gaya apung yang terjadi sama dengan nol. Pada saat volume air penuh gaya apung akan mempengaruhi searah dengan gaya gravitasi dikarenakan bouy dikopel dengan rangka (Mainframe) sehingga gaya apung yang terjadi searah dengan gaya gravitasi dan ikut mendorong tangki kebawah.

Hasil pengujian menunjukan bahwa penerapan gaya gravitasi pada tangki zat cair yang terletak pada elevasi tertentu dari sumbu pompa memiliki potensi besar untuk meningkatkan Head statis tekan pompa atau dapat mereduksi konsumsi daya pada sisi discharge pompa hingga $100 \%$ termasuk rugi-rugi pada sisi discharge dengan jalan memperbesar kapasitas tangki. Disamping itu untuk memperoleh efektifitas gaya gravitasi yang terpakai, maka pemilihan material apung dan batang pendorong harus seringan mungkin.

\section{KESIMPULAN}

Tangki rancangan ini memiliki dampak besar terhadap kebutuhan masyarakat dibidang pengaliran fluida air terutama pemindahan air dari pompa air sehingga memberikan efisiensi dari poma air itu sendiri dan mengurangi energi listrik.

Model tangki pada penelitian ini memiliki keunggulan dibanding tangki konvensional yang dijual dipasaran.

Model tangki rancangan dapat mengurangi konsumsi listrik pada pompa, dilakukan dengan menggunakan tangki yang memiliki tekanan dalam tangki yang lebih rendah dibandingkan tekanan atmosfir, dengan memanfaatkan proses aliran itu sendiri dapat menghemat daya pompa pada sisi tekan.

\section{DAFTAR PUSTAKA}

Buche F.J. \& Hecht, E. 2006. Schaum's Outlines Teori dan Soal-soal Fisika Universitas. Penertbit Erlangga, Jakarta.

M. Galbi Bethalembah, dan Ishak A. 2016. Aplikasi Efek Gaya Apung Dengan Momen Pembalik Pada Model Tangki Rancangan Untuk Menghemat Konsumsi Daya Pompa Pada Sisi Discharge. Bina Teknika, Volume 12 Nomor 2, Edisi Desember 2016, 267-273.

Nur, R., Suyuti, M.A. 2017. Perancangan Mesin-mesin Industri. Penerbit Deepublish (Grup Penerbitan CV. Budi Utama, Yogyakarta.

Sularso \& Tahara, H. 2000. Pompa dan Kompresor, PT Pradnya Paramita, Jakarta,

Tipler A. P. 1996. Fisika untuk Sains dan Teknik, Edisi ke tiga jilid I, Erlangga, Jakarta. 